\title{
Post-Thalamic Stroke Movement Disorders: A Systematic Review
}

\author{
Navnika Gupta Sanjay Pandey \\ Department of Neurology, Govind Ballabh Pant Postgraduate Institute of Medical Education and \\ Research, New Delhi, India
}

\section{Keywords}

Dystonia $\cdot$ Movement disorder $\cdot$ Stroke $\cdot$ Thalamus

\begin{abstract}
Background: After a stroke, movement disorders are rare manifestations mainly affecting the deep structures of the brain like the basal ganglia (44\%) and thalamus (37\%), although there have been case studies of movement disorders in strokes affecting the cerebral cortex also. Summary: This review aims to delineate the various movement disorders seen in association with thalamic strokes and tries to identify the location of the nuclei affected in each of the described movement disorders. Cases were identified through a search of PubMed database using different search terms related to post-thalamic stroke movement disorders and a secondary search of references of identified articles. We reviewed 2,520 research articles and only 86 papers met the inclusion criteria. Cases were included if they met criteria for post-thalamic stroke movement disorders. Case-cohort studies were also reviewed and will be discussed further. Key Messages: The most common post-stroke abnormal movement disorder reported in our review was dystonia followed by hemiataxia. There was a higher association between isch-
\end{abstract}

\section{KARGER}

() 2018 S. Karger AG, Basel

E-Mail karger@karger.com

www.karger.com/ene aemic stroke and movement disorder. Acute onset movement disorders were more common than delayed. The posterolateral thalamus was most commonly involved in postthalamic stroke movement disorders.

(c) 2018 S. Karger AG, Basel

\section{Introduction}

Movement disorders can be primary (genetic) or can occur secondary to conditions like cerebrovascular disease, metabolic causes, autoimmune conditions, iatrogenic (drug-induced), neoplasms (mass effect or paraneoplastic syndromes) or trauma. Cerebrovascular diseases represent up to $22 \%$ of secondary movement disorders, and develop in $1-4 \%$ patients with strokes [1-3]. Poststroke movement disorders are rare manifestations of strokes mainly affecting the deep structures of the brain like the basal ganglia (44\%) and thalamus (37\%), although there have been case studies of movement disorders in strokes affecting the cerebral cortex also [1, 4-6].

This review aims to delineate the types of thalamic strokes (ischaemic, haemorrhagic), and their temporal (acute, subacute, delayed) association with different types 
Fig. 1. Line diagram showing different nuclei of thalamus. LGB, lateral geniculate body; MGB, medial geniculate body.

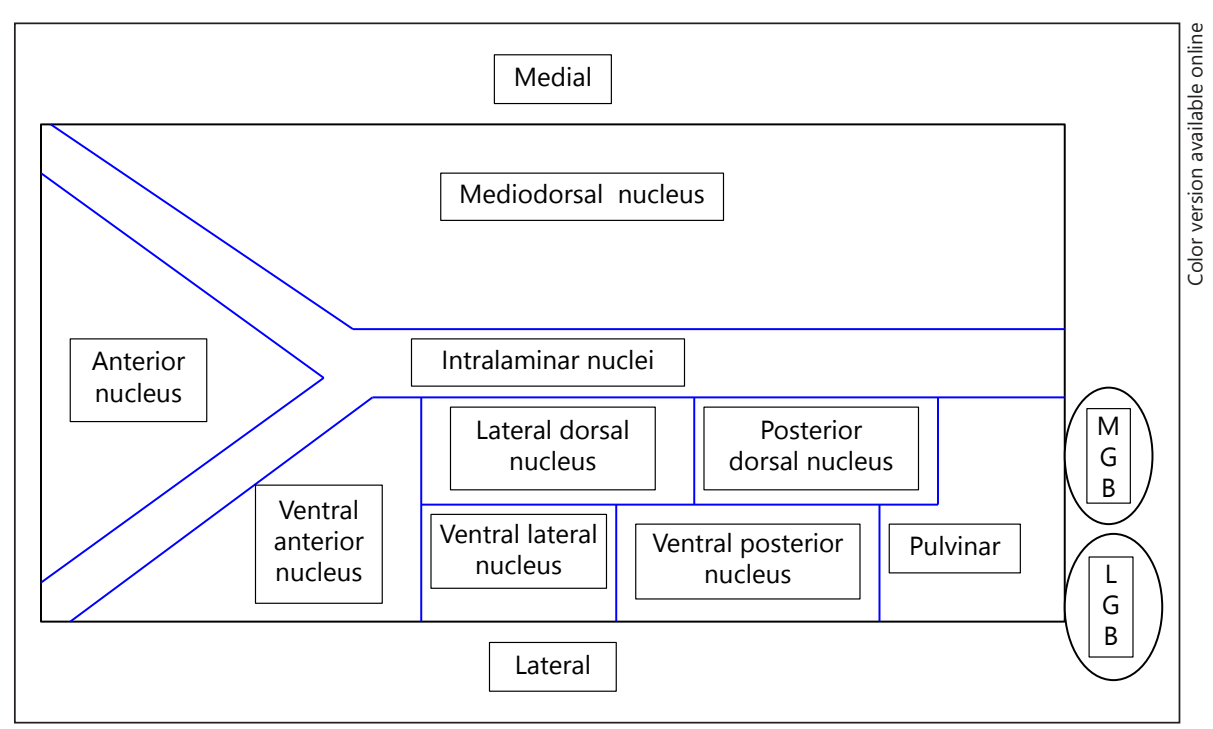

of movement disorders. Using neuroimaging data, we also tried to identify the thalamic areas and nuclei that give rise to movement disorders in thalamic strokes and their relative frequency of involvement that can be helpful in better understanding the internal thalamic circuitry as well as its connections with other brain structures (cerebral hemispheres, basal ganglia and brainstem).

\section{Thalamus: Anatomy and Physiology}

Thalamus is an important subcortical structure made up of various nuclei that relay information between the cerebral cortex and brainstem, cerebellum and the spinal cord. It is divided into anterior, lateral and medial parts by the Y-shaped internal medullary lamina (Fig. 1). The lateral part is subdivided into a ventral and dorsal tier. The ventral tier nuclei (ventral anterior nucleus and ventral lateral nucleus) have important connections with basal ganglia and cerebellum [7]. The intralaminar nuclei are known to influence the activity of corpus striatum. The midline structures of thalamus are a part of a complex circuitry-involving cerebellum, basal ganglia, cerebral cortex and red nucleus. Damage to these nuclei and their connections can give rise to abnormal involuntary movements [8].

The important connections of thalamus that play a role in the generation of abnormal involuntary movements are as follows [9]:

1. The Globus Pallidus interna (GPi) sends inhibitory projections (GABAergic) to ventroanterior and ventrolateral nuclei of thalamus that send excitatory projections (presumably glutamate) to the prefrontal and premotor cortex (Fig. 2).

2. The intralaminar nuclei of thalamus send excitatory inputs (glutaminergic) to the striatum (thalamostriate pathway).

3. A complex pathway from intermediate zone of cerebellar hemisphere to thalamus helps coordinate reciprocal contractions of agonist and antagonist muscles in the peripheral musculature (Fig. 3).

4. The cerebellar pathway from the dentate nucleus projecting to the motor cortex via thalamus has a vital role in performing smooth, coordinated and purposeful patterned movements of agonist and antagonist muscles of the distal limb musculature. It plays an important role in the planning and programming of movements (Fig. 3).

Thalamus receives its blood supply via the branches of posterior cerebral artery, basilar artery and posterior communicating artery [7]. Strokes affecting the aforementioned projections and nuclei or the vessels giving them blood supply can result in abnormal involuntary movements. They can be ischaemic (due to large vessel disease or small vessel lacunes) or haemorrhagic. Lacunes are common in lateral thalamus that receives its blood supply from the thalamogeniculate group of arteries [10]. This region includes the somatosensory nuclei (ventroposteromedial, ventroposterolateral), ventroanterior nucleus and the ventrolateral nucleus that receive the motor projections. There are reports of movement disorders in thalamic strokes in the territory of polar arteries (tuberothalamic arteries) that supply the paramedian thalamus [10]. Haemorrhages in posterolateral thalamus in the territory of thalamogeniculate arteries are the most com- 
Fig. 2. Basal ganglia pathway and its connection with thalamus. DA, dopamine; VL, ventral lateral nucleus; $\mathrm{VA}$, ventral anterior nucleus.

Fig. 3. The cerebellar and thalamic connections: the pathway from the intermediate zone of the cerebellar hemisphere to thalamus helps coordinate reciprocal contractions of agonist and antagonist muscles in the peripheral musculature. The pathway from dentate nucleus to motor cortex via the thalamus has an important role in performing smooth, coordinated and purposeful patterned movements of agonist and antagonist muscles of the distal limb musculature. It plays an important role in the programming and planning of movements. VL, ventral lateral nucleus; VA, ventral anterior nucleus.
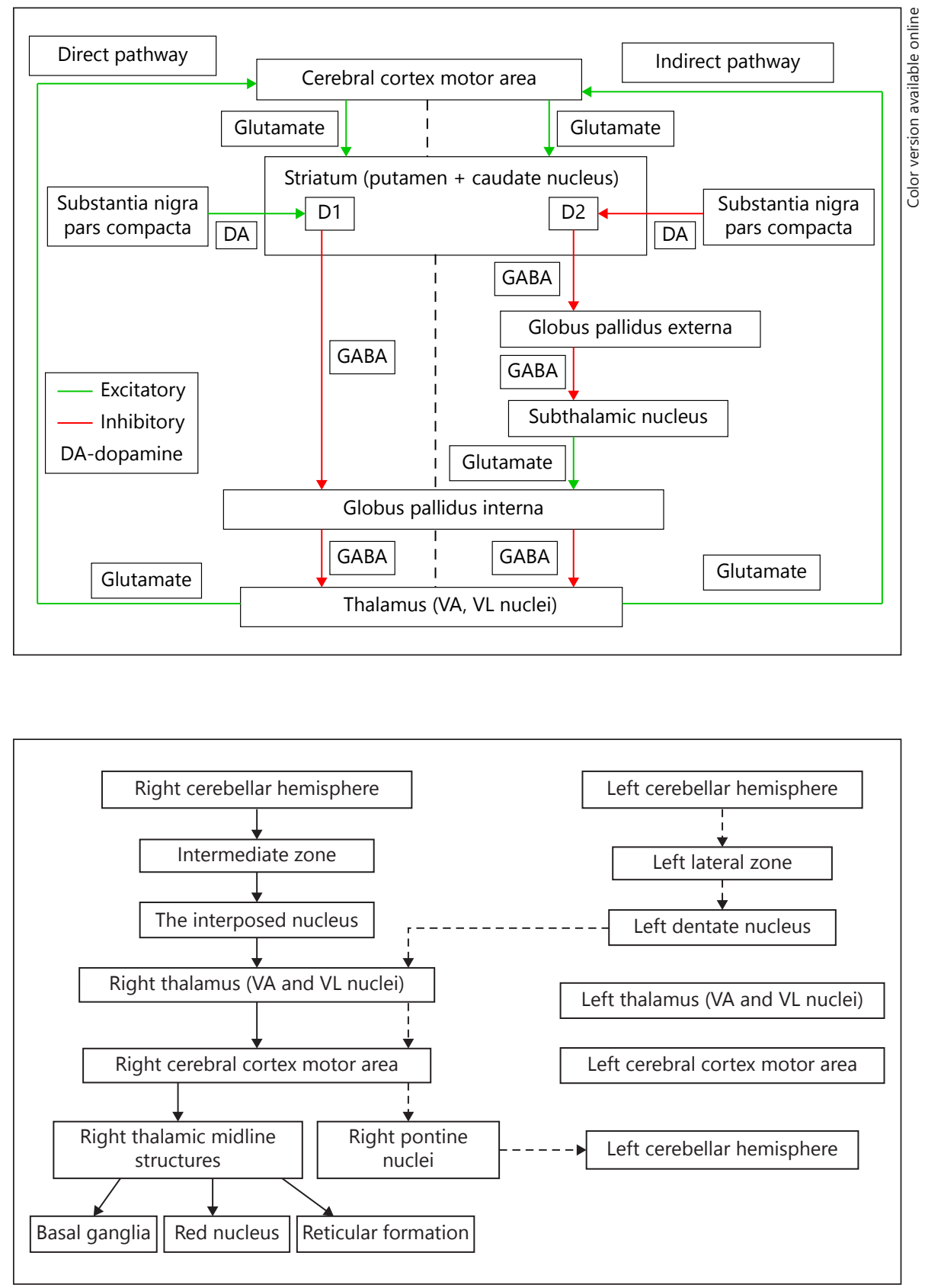

mon and largest type of thalamic hematomas [10]. This may explain the frequent occurrence of abnormal involuntary movements in thalamic haemorrhage.

Thalamic strokes can cause acute movement disorders through the disruption of important connections and fibres. They can result in delayed movement disorders due to the effects of cerebral plasticity. For example, a thalamic infarct in the hand area of the cerebellar projection may lead to reappearing of the hand area in the adjacent

Post-Thalamic Stroke Movement Disorders undamaged area with some recovery of the smooth and coordinated movements. However, this recovery may also be associated with the development of aberrant connections between the remaining nuclei that can generate abnormal involuntary movements.

The abnormal movements described in various case studies and case reports include dystonia, chorea, tremor, hemiataxia, myoclonus, oromandibular dyskinesias and asterixis that can be isolated or may remain as a com- 
bination $[1,3-5,11-34]$. The development of a multitude of abnormal movements suggests that the internal circuitry of thalamus is highly organized and complex and studies are required to elucidate the exact nature of this circuitry. The abnormal movements can be an acute manifestation of the tissue injury caused by stroke or may be delayed because of the degeneration of original tracts and connections between various thalamic nuclei, and thalamus and other brain structures along with development of new and aberrant connections and plastic changes in thalamic organization. Post-stroke movement disorders can be either hyperkinetic or hypokinetic due to changes in neurotransmitter concentration and post-stroke modulation.

\section{Methods}

We searched PubMed on August 19, 2017 with a number of keywords related to post-thalamic stroke movement disorders. The search yielded 2,520 articles that included articles in English and other languages. The articles generated by the keyword search were reviewed and the references generated through these articles were also reviewed. Eighty-six articles met the inclusion criteria that included 47 case reports, 15 case series of up to 5 patients and 24 case series of more than 5 patients. The different movement disorders were defined as:

Dystonia: Dystonia is a movement disorder characterized by sustained or intermittent muscle contractions causing abnormal, often repetitive, movements, postures. Dystonic movements are typically patterned, twisting, and may be tremulous. Dystonia is often initiated or worsened by voluntary action and associated with overflow muscle activation [35].

Hemiataxia: It is characterized by limb incoordination with dysmetria, hypermetria, intention tremor and dysdiadokinesia [36].

Chorea: Chorea is defined as involuntary, irregular, purposeless, nonrhythmic, and non-patterned movements that flow randomly from one part of the body to another [37].

Tremor: Tremor is defined as a rhythmical, regular, sinusoidal oscillation of a body part [37].

Vascular parkinsonism: Parkinsonism as a condition characterized by weakness and slowness of movement accompanied by general rigidity of a non-pyramidal type along with certain features that allowed clinical distinction, including the absence of resting tremor and the presence of dementia and pyramidal signs suggesting a vascular aetiology like stroke [37].

Asterixis: It is a type of negative myoclonus characterized by sudden, brief jerks caused by sudden, brief lapses of muscle contraction in active postural muscles [37].

Athetosis: Athetosis refers to slow, writhing, continuous movements predominantly of distal extremities [37].

Myoclonus: Myoclonic jerks are sudden, brief, shock-like involuntary movements caused by brief muscle contractions (positive myoclonus) or inhibitions (negative myoclonus, or asterixis) [37].
Ballism: Ballism or ballismus consists of repetitive, but constantly varying, large amplitude involuntary movements of the proximal parts of the limbs [37].

Jerky dystonic unsteady hand: It is a delayed hyperkinetic syndrome that presents predominance of myoclonus, dystonia, tremor or choreoathetotic movements but always in a mixed complex presentation [38].

Pseudochoreoathetosis: It is characterized by piano-playing movements of the fingers on an outstretched hand and is attributed to a profound loss of proprioception [39].

Myorhythmia: It consists of fast repetitive contractions that may involve a single muscle or group of muscles. Unlike tremor, they are not completely regular and are slower at about $1-3 \mathrm{~Hz}$ [37].

Clonic perseveration: Clonic perseveration describes the inappropriate repetition of an action, once initiated, in the absence of an on-going cue; the ability to change in response to a new cue is preserved [40].

Stereotypy: Stereotypies consist of purposeless, suppressible, coordinated movements that repeat themselves continually and identically [37].

Akathisia: Akathisia refers to a feeling of inner restlessness, which is relieved by moving [37].

Paroxysomal kinesigenic dystonic choreoathetosis: Paroxysmal kinesigenic dyskinesia is characterized by attacks of chorea, athetosis or dystonia, which are provoked by a sudden movement or startle, last less than $5 \mathrm{~min}$, usually only seconds, and are unassociated with impairment of consciousness. Between-attacks examination is usually normal. The essential features are that they are induced in this way and are brief [37].

Restless leg syndrome: Restless leg syndrome is characterized by unpleasant lower limb sensations, which occur mainly at night and particularly in bed. They are present at rest and are temporarily relieved by movement of the legs, and force the affected individual to restlessly move the legs about in order to attempt to obtain relief [37].

\section{Results}

Eighty-six case reports and studies were reviewed with 341 cases [1, 3, 11-20, 22-30, 32-34, 36, 38, 39, 41-99]. There were 139 men and 117 women, and the data on sex of the patients was not available for 85 cases. The onset was acute in 131 cases, subacute in 21 cases and delayed in 97 cases (Table 1). The data on onset was lacking in 92 cases. The stroke type was ischaemic in 255 cases, haemorrhagic in 70 cases and the type of stroke was not mentioned in 16 cases. On imaging studies used to localize the stroke, thalamus was involved in all 341 cases. In 13 case studies, only CT scan was performed, in 30 case studies, only MRI was done and in 21 case studies, both CT scan and MRI were performed. In the remaining number of case studies, either a CT scan or MRI was done. In one of the studies, the neuroimaging study performed was not mentioned. Along with the thalamus, acute or chronic le- 
Table 1. Movement disorders and their onset: acute onset was $<48 \mathrm{~h}$, subacute onset was $48 \mathrm{~h}$ to 7 days and onset $>7$ days was labelled as chronic. In 92 cases, the data on onset was not provided

\begin{tabular}{|c|c|c|c|c|c|}
\hline $\begin{array}{l}\text { Serial } \\
\text { No. }\end{array}$ & Movement disorder & $\begin{array}{l}\text { Acute } \\
\text { onset }\end{array}$ & $\begin{array}{l}\text { Sub-acute } \\
\text { onset }\end{array}$ & $\begin{array}{l}\text { Delayed } \\
\text { onset }\end{array}$ & $\begin{array}{l}\text { Not } \\
\text { specified }\end{array}$ \\
\hline 1 & Dystonia & 7 & 10 & 65 & 20 \\
\hline 2 & Hemiataxia & 60 & 1 & 1 & 10 \\
\hline 3 & Chorea & 24 & 3 & 21 & 22 \\
\hline 4 & Tremor & 5 & 6 & 42 & 16 \\
\hline 5 & Vascular parkinsonism & - & - & 1 & 51 \\
\hline 6 & Asterixis & 34 & - & 1 & 2 \\
\hline 7 & Athetosis & 2 & 2 & 14 & 17 \\
\hline 8 & Myoclonus & 3 & 1 & 10 & 1 \\
\hline 9 & Ballism & 5 & 1 & 3 & 5 \\
\hline 10 & Myorhythmia & 1 & 1 & 6 & \\
\hline 11 & Jerky dystonic unsteady hand & & & 6 & \\
\hline 12 & Pseudochoreoathetosis & 4 & 1 & 1 & \\
\hline 13 & Clonic perseveration & 1 & 3 & & \\
\hline 14 & Stereotypy & 1 & & 1 & \\
\hline 15 & Bilateral eyelid tremor & 1 & & & \\
\hline 16 & Cerebellar syndrome & & & 1 & \\
\hline 17 & Hemiakathisia & & & & 1 \\
\hline 18 & Jerky dystonia of shoulder & & & 1 & \\
\hline 19 & $\begin{array}{l}\text { Orofacial dyskinesias resembling neuroleptic } \\
\text { induced tardive dyskinesia }\end{array}$ & 1 & & & \\
\hline 20 & Paroxysomal kinesigenic dystonic choreoathetosis & & 1 & & \\
\hline 21 & Restless leg syndrome & 1 & & & \\
\hline
\end{tabular}

Table 2. The brain structures that were involved with thalamus in strokes and their frequency of involvement. Acute lesions were the ones reported at the time of presentation. Chronic lesions were any previous underlying lesions

\begin{tabular}{llll}
\hline Serial No. & Structures involved & Acute lesion & Chronic lesion \\
\hline 1 & Thalamus and internal capsule & 82 & 1 \\
2 & Thalamus and subthalamic region & 12 & 1 \\
3 & Thalamus and basal ganglia & 19 & 4 \\
4 & Thalamus and cerebellum & 8 & 1 \\
5 & Thalamus and brainstem & 10 & 1 \\
6 & Thalamus and cerebral hemisphere & 43 & 3 \\
\hline
\end{tabular}

sions were noted in the internal capsule, subthalamic region, basal ganglia, cerebellum, brainstem and cerebral hemispheres in some of the cases as described in Table 2. The patients who had lesions outside the thalamus also presented with various neurological deficits. Patients with lesions in the internal capsule had the neurological findings of hemiparesis, hemihypesthesia (that included loss of all sensations or loss of only touch, vibration or proprioception), upper motor neuron seventh cranial nerve palsy and dysarthria. Patients with lesions in cerebral hemisphere were noted to have hemiparesis, hemi- hypesthesia (that included loss of all sensations or loss of only touch, vibration or proprioception), upper motor neuron seventh cranial nerve palsy, dysarthria, aphasia and hemianopsia. Brainstem lesions presented with signs like third cranial nerve dysfunction, altered mental status, supranuclear gaze palsy, upward nystagmus, pseudoabducens palsy or vertical gaze palsy. Cerebellar lesions presented with dysarthria or dysmetria on finger-to-nose testing. The nucleus was identified according to classification given in the atlas of Hassler and the corresponding classification in Hirai and Jones [100, 101]. 
Movement Disorders Following Thalamic Stroke

There were cases of dystonia (102), hemiataxia (72), chorea (71), tremor (69), vascular parkinsonism (55), asterixis (37), athetosis (35), myoclonus (15) and ballism (14). Some other types of movement disorders were also described, but the number of cases of each one of them was less than 10. These included jerky dystonic unsteady hand (6), pseudochoreoathetosis (6), myorhythmia (4), clonic perseveration (4), stereotypy (2), bilateral eyelid tremor (1), cerebellar syndrome (1), hemiakathisia (1), jerky dystonia of shoulder (1), orofacial dyskinesia resembling neuroleptic induced tardive dyskinesia (1), paroxysomal kinesigenic dystonic choreoathetosis (1) and restless leg syndrome (1).

\section{Dystonia}

One hundred and two cases of dystonia were described with isolated dystonia in 32 cases and in combination with other movement disorders (chorea, athetosis, tremor, myoclonus, myorhythmia, ballism, stereotypy, parkinsonism, ataxia and asterixis) in 70 cases. The body distribution of dystonia was focal (51), hemi (7), bilateral (6), segmental (3) or multifocal (2). One case of segmental dystonia resembled Meige's syndrome [92]. Dystonic spasm was reported in one case and myoclonic dystonia was reported in 5 cases [49, 72].

\section{Hemiataxia}

Seventy-two cases of hemiataxia were described. Hyperesthetic ataxic hemiparesis was described in 8 cases, hyperesthetic hemiataxia was described in 24 cases, ataxic hemiparesis was described in 11 cases and sensory hemiataxia was described in 5 cases [14, 42, 46, 47, 50, 51, $54,55,58,88,102]$. Isolated hemiataxia was described in 3 cases. Other movement disorders described in association with hemiataxia were asterixis, rubral tremor and dystonia.

\section{Chorea}

There were 70 cases of chorea and majority of them (68) were hemichorea. Isolated hemichorea was observed in 17 cases and in 51 cases other movement disorders were also present.

\section{Tremor}

Sixty-nine cases of tremor were described, which was isolated in 21 cases and in combination with other movement disorders in 48 cases. In 7 cases, there was improve- ment or disappearance of tremor following thalamic stroke $[45,48,73,78,82,86,98]$. Bilateral tremor was reported in 2 cases. Types of tremors described were resting, postural, action and intention, either alone or in combination.

\section{Vascular Parkinsonism}

Fifty-five cases of vascular Parkinsonism were identified. Among them, 51 cases were a part of a large study on association of cerebral small vessel disease with vascular Parkinsonism [96]. In this study, significant association was found between mixed lacunar infarcts (involving both basal ganglia and thalamus) and gait/balance dysfunction and bradykinesia. There was a significant association between cerebral microbleeds and mild Parkinsonism signs. However, no particular area or nucleus of thalamus was identified. Parkinsonism signs were believed to have appeared due to the disruption of connections of basal ganglia-thalamo-frontal cortical circuits. In one case, parkinsonism was associated with dystonia. In 2 cases, parkinsonian resting tremor and parkinsonism disappeared following thalamic infarction.

\section{Asterixis}

Thirty-seven cases of asterixis were identified. Isolated asterixis was present in 25 cases, associated hemiataxia was present in 11 cases and dystonia was present in one case.

\section{Athetosis}

Thirty-five cases of athetosis were reported. The associated movement disorders were chorea (31), dystonia (31) and action tremor (24). No case of isolated athetosis was reported.

\section{Myoclonus}

Fifteen cases of myoclonus were identified, which was isolated in 3 cases and associated with other movement disorders in 10 cases. One case of myoclonus presenting as startle syndrome and one case of palatal myoclonus with right arm myoclonus were reported. Interestingly, the case with palatal myoclonus lacked a midbrain lesion.

\section{Ballism}

Fourteen cases of ballism were described. A single case of monoballism of right leg was reported and all other patients had hemiballism, which was isolated in one case and associated with other movement disorders in 12 cases. 


\section{Other Movement Disorders}

There were reports of movement disorders that were previously unreported in thalamic strokes and the number of cases of each of them was less than 10 .

\section{Thalamic Regions and Nuclei Involved in Movement Disorders}

The most common thalamic region involved was posterolateral and the most common nucleus involved was ventrolateral followed by ventroposterior (Tables 3,4 ). Dystonia was most commonly involved with the posterolateral part of the thalamus and the most frequently involved nucleus was ventroposterior. The lateral thalamus was the most frequently involved part with hemiataxia and the most commonly involved nucleus was ventrolateral. The most frequently involved thalamic region for chorea was posterolateral and the most frequently involved nuclei were ventroposterior and ventrolateral. Tremor was most frequently involved with the posterolateral part, and the most frequently involved nuclei were ventroposterior and ventrolateral. The most frequently involved nuclei with asterixis were ventrolateral and ventroposterior. In the ventroposterior nucleus, the lateral part (ventroposterolateral) was more frequently involved. There was no isolated lesion for athetosis, but the ventroposterior and ventrolateral nuclei were the most frequently involved. The centromedian, ventroposterior and ventrolateral were the most frequently identified nuclei in myoclonus. No thalamic regions or nuclei were identified in particular for ballism. The other movement disorders had involvement of different thalamic areas and nuclei.

\section{Discussion}

In our review, there were 102 cases of dystonia, 72 cases of hemiataxia, 70 cases of chorea, 69 cases of tremor, 55 cases of vascular Parkinsonism, 37 cases of asterixis, 35 cases of athetosis, 15 cases of myoclonus and 14 cases of ballism. The onset was acute in 131 cases, subacute in 21 cases and delayed in 97 cases. The data on onset was not available in 92 cases. Kim [79] reported 35 patients with mixed involuntary movements and the onset was delayed in all the cases. In the study of Alarcon et al. [3], the onset of abnormal movements was within 4.3 days of stroke in 20 patients with chorea and after 15 days of stroke in 36 patients with dystonia (16), tremor (14) and parkinsonism (6). In our review, acute onset movement disorders were more common than delayed. This is consistent with the
Table 3. Thalamic regions involved in thalamic strokes and the frequency of involvement of each of the regions

\begin{tabular}{ll}
\hline Thalamic region involved & Number of cases \\
\hline Posterolateral & 72 \\
Lateral & 27 \\
Posterior & 15 \\
Paramedian & 12 \\
Mid to posterior & 10 \\
Dorsolateral & 6 \\
Ventral & 3 \\
Ventrolateral & 3 \\
Anterior & 2 \\
Dorsal & 2 \\
Medial & 2 \\
Superior centrolateral & 1 \\
Superior lateral & 1 \\
\hline
\end{tabular}

Table 4. Thalamic nuclei involved in thalamic strokes and the frequency of involvement of each of them. The nuclei in the classification of Hirai and Jones that corresponded with those of Atlas of Hassler are placed together

\begin{tabular}{lc}
\hline Thalamic nuclei involved & Number of cases \\
\hline VL & 109 \\
VP/Vc & 100 \\
VPL/Zc & 44 \\
CM/Ce & 33 \\
Pulvinar & 23 \\
VLp/Vim/Voi/Zim/Dim & 23 \\
LP/Dc & 21 \\
VPM/Vci & 16 \\
DM/M & 12 \\
VA/Lpo & 12 \\
CL/Lam & 7 \\
VLa/Do/Voa/Vop/Zo & 7 \\
LD & 5 \\
Parafascicular & 5 \\
Anterior & 4 \\
Nucleus limitans/Li & 3 \\
Reticular & 2 \\
VM & 1 \\
\hline
\end{tabular}

VL, ventral lateral nucleus; VP, ventral posterior nucleus; Vc, nucleus ventral caudalis; VPL, nucleus ventral posterior lateral; $\mathrm{Zc}$, nucleus zentrocaudalis; CM, centromedian nucleus; VLp, nucleus ventral lateral posterior; Vim, ventral intermediate nucleus; Voi, nucleus ventrooralis intermedius; Zim, nucleus zentrolateralis intermedius; Dim, dorsal intermediate nucleus; LP, lateral posterior nucleus; Dc, dorsal caudal nucleus; VPM, ventral posterior medial nucleus; Vci, nucleus ventrocaudalis internus; DM, dorsomedial nucleus; $\mathrm{M}$, medial nucleus; VA, ventral anterior nucleus; Lpo, nucleus lateropolaris; $\mathrm{CL}$, central lateral nucleus; Lam, nuclei intralaminaris; Vla, nucleus ventral lateral anterior; Do, dorsal oral nucleus; Voa, ventral oral anterior nucleus; Vop, ventral oral posterior nucleus; $\mathrm{Zo}$, nucleus zentro-oralis; LD, dorsolateral nucleus; Li, nucleus limitans; VM, ventral medial nucleus. 
study of D'Olhaberriague et al. [15], where 19 out of 22 patients had acute onset of abnormal movements. This may be due to a late-look bias and under-reporting of abnormal movements in the acute phase of stroke due to the late presentation of patients at the healthcare facility. Another explanation can be a recall bias due to the poor recollection of the presence of abnormal movements in the acute phase of stroke by the patients and these movements thereafter subsided spontaneously. Alarcon et al. [3] reported chorea and D'Olhaberriague et al. [15] reported hemichoreahemiballismus as the most common acute abnormal involuntary movements. In our review, dystonia was the most common post thalamic stroke movement disorder; however, the most common acute movement disorder was hemiataxia and the second most common was asterixis.

The type of stroke as identified in our review was of the ischaemic type in 255 cases and haemorrhagic in 70 cases; the data on the type of stroke was lacking in 16 cases. This was in contrast to the study reported by Kim [79], where thalamic haemorrhage was more common in post-stroke movement disorders. However, our findings are consistent with those of the Lausanne stroke registry, where post-stroke movement disorders had a greater association with thalamic infarcts [1]. The findings in our review are also consistent with those of the review of Mehanna and Jankovic [2], where a higher association between ischaemic stroke and movement disorders was reported. In our review, the onset of movement disorders was acute in 104 cases, subacute in 16 cases, delayed in 70 cases and not specified in 65 cases of ischaemic stroke. Based on this information, we hypothesize that acute disruption of tracts between thalamus, basal ganglia and cerebellum may be the main pathogenic mechanism for the generation of movement disorders in thalamic infarcts. In haemorrhagic lesions, the onset was acute in 25 cases, subacute in 5 cases, delayed in 23 cases and not specified in 17 cases. Hence, we could not establish a definite association.

We will now discuss the movement disorders in detail. The most common reported movement disorder was dystonia and focal dystonia was the most common type. Dystonia when present in combination with other movement disorders was most commonly associated with tremor and chorea. In these cases, the most common region affected was the posterolateral thalamus, and the lesion was localized to ventroposterior and ventrolateral nuclei in the majority. These findings are consistent with those reported by Kim [79]. In our review, the centromedian nucleus was involved in 21 cases of dystonia. In the study of Lehericy et al. [49], it was involved in all cases of thalamic dystonia. The centrome- dian nucleus is a part of the intralaminar nuclei that project to striatum and form the thalamostriate pathway [8]. This nucleus is considered a negative regulator of cortico-striato-pallido-thalamo-cortical loop with inhibitory influences on ventro lateral nucleus $[103,104]$. The centromedian nucleus receives inputs from pedunculopontine nucleus and the lesions of these fibres can result in dystonia $[105,106]$. In recent studies, the pedunculopontine complex has been shown to affect the ventrolateral nuclei of thalamus [107]. Hence, lesions affecting this nucleus can result in increased thalamocortical drive and hence, play an important role in thalamic dystonia. Recently, Neychev et al. [108] proposed a network model for dystonia and suggested cerebellar dysfunction as a key component of this model. As mentioned previously, the motor part of cerebellum is responsible for smooth and coordinated movements of agonist and antagonist muscles in distal limb musculature and it sends projections to thalamus [9] (Fig. 3). In line with this model, damage to the cerebello-thalamic projections can lead to an imbalance between agonist and antagonist muscles leading to dystonia.

Hemiataxia was the second most common movement disorder and the most common acute movement disorder following thalamic stroke. This is in contrast to the studies of Alarcon et al. [3] and D'Olhaberriague et al. [15], where chorea and hemichorea-hemiballismus were reported as the most common acute movement disorders respectively. Hemiataxia was described as ataxic hemiparesis, hypesthetic hemiataxia, hypesthetic ataxic hemiparesis or sensory hemiataxia $[14,41,42,46,47,50,51,54$, $55,58,63]$. Dobato et al. [14] reported 5 patients with sensory ataxic hemiparesis following thalamic haemorrhage, where all patients had loss of deep sensations like joint and position sense.

Chorea was described in 70 cases and was the third most common movement disorder in our review. It was acute onset in 24 cases and delayed onset in 21 cases. The onset was subacute in 3 cases and not mentioned in 22 cases. The most common thalamic region involved was posterolateral. The most common thalamic nuclei involved were ventroposterior and ventrolateral. In our review, there were 14 cases of ballism. However, no thalamic region or nucleus was found to be particularly associated with ballism. Chorea and ballism were the most commonly identified in lesions of subthalamic nucleus in the review of Lee and Marsden [21]. D'Olhaberriague et al. [15] reported that hemiballism-hemichorea were most commonly associated with thalamic lesions in their series. The GABAergic fibres from the basal ganglia pass via 
the ventrolateral nucleus and hence, ultimately to the motor cortex. Acute lesions of these fibres may cause the disinhibition of the thalamus resulting in the hyperkinetic movement disorder of chorea-ballism. In our review, there were also delayed cases of chorea-ballism following thalamic stroke. The disruption of the GABAergic fibres can explain the reason for acute chorea, but what is not known is the type of neuroplastic changes that take place in thalamus following stroke, which lead to delayed movement disorders. It has been hypothesized that the regenerated neurons release a different neurotransmitter or lead to the generation of an excitatory foci that causes the chorea-ballism [15].

Tremor was described in 69 patients. Tremor was isolated in 21 patients and associated with other movement disorders in 48 patients. No case of isolated tremor following thalamic stroke was reported by Lee [21] (62 patients) and Kim [79] (35 patients) in their respective studies. Mehanna and Jankovic [2] reported isolated tremor as a rare occurrence. Our observation was different from these previously reported findings. The most common type of tremor in our review is action tremor (33 cases) followed by rubral tremor (12 cases). Stroke affecting dentate-rubro-thalamic tract may be responsible for them. Tremor and dystonia frequently occurred together (41 patients) and the posterolateral thalamus was the most common region affected. Like in dystonia, ventroposterior and ventrolateral nuclei were most frequently involved in the production of tremor. Based on these findings, we hypothesized that the lesions in these cases probably involved large areas of posterolateral thalamus. This is because dystonia and tremor were also reported as isolated findings. If these movements are present as isolated findings, then the fibres that are affected are also present in certain pockets in ventrolateral and ventroposterior nuclei. Only when the lesion is large enough, these movement disorders can be produced in combination. Future functional studies are required to localize these pockets in the aforementioned nuclei. Most cases of dystonia and tremor had delayed onset. This makes us believe that plastic changes, neurodegeneration and the formation of aberrant connections in thalamus with alteration in neurotransmitter modulation following stroke may be the main mechanism responsible for these movement disorders.

Vascular parkinsonism was described in 55 cases out of which 51 cases were part of a single large study on the appearance of mild parkinsonian signs post-stroke [96]. Hatate et al. [96] reported that mixed lacunar infarcts and deep cerebral bleeds involving basal ganglia and thalamus were associated with mild parkinsonism, gait disturbanc-

Post-Thalamic Stroke Movement Disorders es and bradykinesia. However, there was no data on the affected thalamic region and nuclei. In the cortico-basal ganglia-thalamo-cortical loop, the GPi sends basal ganglia output to thalamus and then fibres from thalamus project to the motor cortex. The fibres from GPi pass through the ventroanterior and ventrolateral nuclei of thalamus before projecting to the motor cortex. Hence, lesions affecting these tracts can result in the appearance of signs of vascular parkinsonism. In acute stroke, the infarct or haemorrhage can damage the projections from GPi to thalamus and cause vascular parkinsonism. Delayed vascular parkinsonism can result from neurodegeneration with loss of GABAergic neurons and projections from basal ganglia to thalamus resulting in decreased disinhibition of thalamus and hence, reduced thalamocortical drive. We put forth these theories based on our current knowledge of the basal ganglia-thalamic circuitry and further studies are required to test these hypotheses.

There were 37 cases of asterixis [77, 80]. Thirty-four cases had an acute onset following thalamic stroke and most of the cases resolved spontaneously over a period of 10 days. We found that asterixis had a higher prevalence than reported in previous studies. This observation is consistent with that made by the Lausanne stroke registry that the prevalence of unilateral asterixis is underestimated and has to be looked for and recognized in the acute phase of stroke [1]. One possible reason for the underreporting can be the presence of a late-look bias. Asterixis is a transient phenomenon that generally subsides over a week, that is, about 10 days. Patients often do not present in the acute phase of stroke and hence, the asterixis may have resolved by the time the patient presents to the healthcare facility. Another reason can be the presence of a recall bias as the patient may focus on the more pronounced manifestations of hemiparesis, facial deviation or speech deficits and hence, may not notice the subtle asterixis. Kim [80] attributed the discrepancy to the fact that not every patient is examined with outstretched hands. However, this seems unlikely as patients are generally examined with outstretched hands to look for the presence of drift. The most common nucleus affected in asterixis was the ventrolateral nucleus. Hence, the cerebello-rubro-thalamo-cortical projections may play a role in the pathophysiology of asterixis as reported by Kim [80] and Tatu [77], who attributed the appearance of asterixis to loss of postural control.

Athetosis was present in 35 cases, but all were associated with dystonia or chorea. Since, isolated cases of athetosis have not been reported, it is difficult to explain the exact pathogenesis of athetosis. In the case series pub- 
lished by Kim [79], athetosis was attributed to the loss of proprioception. The lesion of the ventroposterior nuclei can explain this. However, no motor pathway has been clearly defined in the lesions of athetosis. Further studies using animal models and imaging studies are required to further elucidate the pathogenesis of athetosis.

There were 15 cases of myoclonus and the nuclei involved were centromedian (9), ventrolateral posterior (9) and ventroposterior (9). The type of myoclonus in these cases was probably subcortical. Some insight as to how the above-mentioned nuclei can cause myoclonus can come from myoclonus-dystonia syndrome, where the involvement of basal ganglia has been speculated. The centromedian nucleus is a negative regulator of the cortico-pallidostriato-pallido-thalamo-cortical loop and inhibits the ventrolateral nuclei of the thalamus [109]. Lesions of the centromedian nucleus result in the withdrawal of the negative influence this nucleus has on the ventrolateral nuclei that can lead to generation of hyperkinetic movement disorders like dystonia and possibly myoclonus. However, if this is true, then every case of dystonia should be associated with myoclonus, but that is not the case. Hence, the missing dots in this puzzle should be joined to understand the pathophysiology of subcortical myoclonus, especially myoclonus seen in basal ganglia and thalamic lesions.

In our review, posterolateral thalamus was involved in a maximum number of cases, which is consistent to the observation of Kim [79]. The ventrolateral (109 cases) and ventroposterior (ventrocaudal) nuclei (100 cases) had the highest frequency of involvement. The centromedian nucleus was also involved in a significant (33 cases) number of cases. Lehericy et al. [24] reported the involvement of the centromedian nucleus in a significant number of cases of dystonia and myoclonus. Further studies are required to elucidate the role of this nucleus in postthalamic stroke movement disorders.

\section{Summary}

The following are some important observations from our review:

1. The most common abnormal movement disorder in our review was dystonia followed by hemiataxia.

2. There was a higher association between ischaemic stroke and movement disorder.

3. Acute onset movement disorders were more common than delayed.

4. The most common acute movement disorder was hemiataxia.

5. The second most common acute movement disorder was asterixis that had an unusually high frequency than previously thought and should be looked for in patients following acute stroke.

6. The posterolateral thalamus was most commonly involved in post-thalamic stroke movement disorders followed by lateral and posterior thalamus.

7. The ventrolateral nuclei had the highest frequency of involvement.

\section{Statement of Ethics}

The manuscript has been prepared according to the ethical norms of the institute and the journal.

\section{Disclosure Statement}

The authors have no conflicts of interest to disclose. There were no funding sources for this work.

\section{Author Contribution}

Dr. Navnika Gupta and Dr. Sanjay Pandey contributed to manuscript preparation by writing the first draft, review and critique.

\section{References}

1 Ghika-Schmid F, Ghika J, Regli F, Bogousslavsky J: Hyperkinetic movement disorders during and after acute stroke: the Lausanne Stroke Registry. J Neurol Sci 1997;146: 109-116.

2 Mehanna R, Jankovic J: Movement disorders in cerebrovascular disease. Lancet Neurol 2013;12:597-608.

- 3 Alarcón F, Zijlmans JCM, Dueñas G, Cevallos N: Post-stroke movement disorders: report of 56 patients. J Neurol Neurosurg Psychiatry 2004;75:1568-1574.
4 Kim JS: Involuntary movements after anterior cerebral artery territory infarction. Stroke 2001;32:258-261.

5 Kim JS, Lee MC: Writing tremor after discrete cortical infarction. Stroke 1994;25:22802282.

6 Park J: Movement disorders following cerebrovascular lesion in the basal ganglia circuit. J Mov Disord 2016;9:71-79.

7 Snell RS: Clinical Neuroanatomy. Wolters Kluwer Health/Lippincott Williams \& Wilkins, 2010.
8 Barrett KE, Barman SM, Boitano S, Brooks H Ganong's Review of Medical Physiology, 24th Edition. Mcgraw-Hill, 2012.

9 Hall J, Hall J: Guyton and Hall Textbook of Medical Physiology, (ed 12). Saunders Elsevier, 2010.

10 Caplan L: Caplan's Stroke: A Clinical Approach, 4th Edition. Saunders Elsevier, 2009.

11 Álvarez M, Quintanal N, Díaz A, et al: Dystonia and tremor secondary to thalamic infarction successfully treated with thalamotomy of the ventralis intermedius nucleus. Mov Disord 2014;29:1188-1190. 
12 Camac A, Greene P, Khandji A: Paroxysmal kinesigenic dystonic choreoathetosis associated with a thalamic infarct. Mov Disord 1990;5:235-238.

13 Dewey RB Jr, Jankovic J: Hemiballism-hemichorea: clinical and pharmacologic findings in 21 patients. Arch Neurol 1989;46:862867.

14 Dobato JL, Villanueva JA, Giménez-Roldán S: Sensory ataxic hemiparesis in thalamic hemorrhage. Stroke 1990;21:1749-1753.

-15 D’Olhaberriague L, Arboix A, Martí-Vilalta JL, Moral A, Massons J: Movement disorders in ischemic stroke: clinical study of $22 \mathrm{pa}-$ tients. Eur J Neurol 1995;2:553-557.

16 Ferbert A, Gerwig M: Tremor due to stroke. Mov Disord 1993;8:179-182.

17 Fung VSC, Morris JGL, Leicester J, Soo YS, Davies L: Clonic perseveration following thalamofrontal disconnection: a distinctive movement disorder. Mov Disord 1997;12: 378-385.

18 Kim HJ, Lee MC, Kim JS, et al: Lingual dystonia as a manifestation of thalamic infarction. Mov Disord 2009;24:1703-1704.

19 Krystkowiak P, Martinat P, Cassim F, et al: Thalamic tremor: correlations with three-dimensional magnetic resonance imaging data and pathophysiological mechanisms. Mov Disord 2000;15:911-918.

20 Lee MS, Lee SA, Heo JH, Choi IS: A patient with a resting tremor and a lacunar infarction at the border between the thalamus and the internal capsule. Mov Disord 1993;8:244246

21 Lee MS, Marsden CD: Movement disorders following lesions of the thalamus or subthalamic region. Mov Disord 1994;9: 493-507.

22 Lee MS, Kim YD, Kim JT, Lyoo CH: Abrupt onset of transient pseudochoreoathetosis associated with proprioceptive sensory loss as a result of a thalamic infarction. Mov Disord 1998; 13:184-186.

23 Lee SJ, Kim JS, Song IU, An JY, Kim YI, Lee KS: Poststroke restless legs syndrome and lesion location: anatomical considerations. Mov Disord 2009;24:77-84.

24 Lehéricy S, Grand S, Pollak P, et al: Clinical characteristics and topography of lesions in movement disorders due to thalamic lesions. Neurology 2001;57:1055-1066.

-25 Lera G, Scipioni O, Garcia S, Cammarota A, Fischbein G, Gershanik O: A combined pattern of movement disorders resulting from posterolateral thalamic lesions of a vascular nature: a syndrome with clinicoradiologic correlation. Mov Disord 2000;15 120-126.

26 Louis ED, Lynch T, Ford B, Greene P, Bressman SB, Fahn S: Delayed-onset cerebellar syndrome. Arch Neurol 1996;53:450-454.

-27 Micheli F, Cersósimo G, Palacios C, Scorticati MaC, Tenembaum S, Tipoli J: Dystonia and tremor secondary to a pediatric thalamic stroke. Parkinsonism Relat Disord 1998;4 119-122.
28 Nijssen PCG, Tijssen CC: Stimulus-sensitive paroxysmal dyskinesias associated with a thalamic infarct. Mov Disord 1992;7:364366.

29 Perren F, Clarke S, Bogousslavsky J: The syndrome of combined polar and paramedian thalamic infarction. Arch Neurol 2005;62: 1212-1216.

30 Qureshi F, Morales A, Elble RJ: Tremor due to infarction in the ventrolateral thalamus. Mov Disord 1996;11:440-444.

31 Scott BL, Jankovic J: Delayed-onset progressive movement disorders after static brain lesions. Neurology 1996;46:68-74.

32 Sibon I, Burbaud P: Risus sardonicus after thalamic haemorrhage. Mov Disord 2004;19: 829-831.

33 Tan EK, Chan LL, Auchus AP: Complex movement disorders following bilateral paramedian thalamic and bilateral cerebellar infarcts. Mov Disord 2001;16:968-970.

34 Walker RH: Jerky dystonic shoulder following infarction of the posterior thalamus. J Clin Mov Disord 2015;2:12.

35 Albanese A, Bhatia K, Bressman SB, et al: Phenomenology and classification of dystonia: a consensus update. Mov Disord 2013;28:863873.

36 Kim JS: Delayed onset hand tremor caused by cerebral infarction. Stroke 1992;23:292-294.

37 Donaldson I, Marsden CD, Schneider S: Marsden's Book of Movement Disorders. OUP Oxford, 2012.

38 Ghika J, Bogousslavsky J, Henderson J, Maeder P, Regli F: The "jerky dystonic unsteady hand": a delayed motor syndrome in posterior thalamic infarctions. J Neurol 1994;241: 537-542.

-39 Kim JW, Kim SH, Cha JK: Pseudochoreoathetosis in four patients with hypesthetic ataxic hemiparesis in a thalamic lesion. J Neurol 1999;246:1075-1079.

40 Liepmann H: Die perseveration; in Liepmann $\mathrm{H}$ (ed): Ueber Storungen des Handelns bei Gerhirnkranken. Berlin, Karger, 1905, pp 115-127.

41 Perman GP, Racy A: Homolateral ataxia and crural paresis: case report. Neurology 1980; 30:1013-1015.

42 Bogousslavsky J, Regli F, Ghika J, Feldmeyer JJ: Painful ataxic hemiparesis. Arch Neurol 1984;41:892-893.

43 Pettigrew LC, Jankovic J: Hemidystonia: a report of 22 patients and a review of the literature. J Neurol Neurosurg Psychiatry 1985;48: 650-657.

44 Schlitt M, Brown JW, Zeiger HE, Galbraith JG: Appendicular tremor as a late complication of intracerebral hemorrhage. Surg Neurol 1986;25:181-184

45 Dubois B, Pillon B, De Saxce H, Lhermitte F, Agid Y: Disappearance of parkinsonian signs after spontaneous vascular "thalamotomy". Arch Neurol 1986;43:815-817.

46 Verma AK, Maheshwari MC: Hypestheticataxic-hemiparesis in thalamic hemorrhage. Stroke 1986;17:49-51.
47 Murthy JM: Ataxic hemiparesis-ventrolateral nucleus of the thalamus: yet another site of lesion. Stroke 1988;19:122.

48 Duncan R, Bone I, Melville ID: Essential tremor cured by infarction adjacent to the thalamus. J Neurol Neurosurg Psychiatry 1988;51:591-592.

49 Lehéricy S, Vidailhet M, Dormont D, et al: Striatopallidal and thalamic dystonia A magnetic resonance imaging anatomoclinical study. Arch Neurol 1996;53:241250

50 Lee N, Roh JK, Myung H: Hypesthetic ataxic hemiparesis in a thalamic lacune. Stroke 1989; 20:819-821.

51 Boiten J, Lodder J: Ataxic hemiparesis following thalamic infarction. Stroke 1990;21:339340

52 Combarros O, Gutiérrez A, Pascual J, Berciano J: Oral dyskinesias associated with bilateral thalamo-capsular infarction. J Neurol Neurosurg Psychiatry 1990;53:168-169.

53 Maruyama T, Hashimoto T, Miyasaka M Yanagisawa N: [A case of thalamo-subthalamic hemorrhage presenting monoballism in the contralateral lower extremity]. Rinsho shinkeigaku 1992;32:1022-1027.

54 Emori T, Kuriyama Y, Imakita S, Sawada T: Ataxic hemiparesis following thalamic lacunar infarction. Intern Med 1992;31:889892

55 Melo TP, Bogousslavsky J: Hemiataxia-hypesthesia: a thalamic stroke syndrome. J Neurol Neurosurg Psychiatry 1992;55:581584

56 Gutrecht JA, Zamani AA, Pandya DN: Lacunar thalamic stroke with pure cerebellar and proprioceptive deficits. J Neurol Neurosurg Psychiatry 1992;55:854-856

57 Lazzarino LG, Nicolai A: Late onset unilateral asterixis secondary to posterior cerebral artery infarction. Ital J Neurol Sci 1992;13:361364

58 Melo TP, Bogousslavsky J, Mouline T, Nader J, Regli F: Thalamic ataxia. J Neurol 1992;239: 331-337.

59 Mossuto-Agatiello L, Puccetti G, Castellano AE: "Rubral" tremor after thalamic haemorrhage. J Neurol 1993;241:27-30.

60 Mano Y, Nakamuro T, Takayanagi T, Mayer RF: Ceruletide therapy in action tremor following thalamic hemorrhage. J Neurol 1993; 240:144-148.

61 Vidakovic A, Dragasevic N, Kostic VS: Hemiballism: report of 25 cases. J Neurol Neurosurg Psychiatry 1994;57:945-949.

62 Solomon DH, Barohn RJ, Bazan C, Grissom J: The thalamic ataxia syndrome. Neurology 1994:44:810-810.

63 Moulin T, Bogousslavsky J, Chopard JL, et al: Vascular ataxic hemiparesis: a re-evaluation. J Neurol Neurosurg Psychiatry 1995;58:422427.

64 Otto S, Büttner T, Schöls L, Windmeier DT, Przuntek H: Head tremor due to bilateral thalamic and midbrain infarction. J Neurology 1995;242:608-610. 
65 Gille M, Van den Bergh P, Ghariani S, Guettat L, Delbecq J, Depre A: Delayed-onset hemidystonia and chorea following contralateral infarction of the posterolateral thalamus. A case report. Acta Neurol Belg 1996;96:307-311.

-66 Kostià VS, Stojanovié-Svetel M, Kacar A: Symptomatic dystonias associated with structural brain lesions: report of 16 cases. Can J Neurol Sci 1996;23:53-56.

67 Miwa H, Hatori K, Kondo T, Imai H, Mizuno $\mathrm{Y}$ : Thalamic tremor: case reports and implications of the tremor-generating mechanism. Neurology 1996;46:75-79.

-68 Motoi Y, Hattori Y, Miwa H, Shina K, Mizuno Y: [A case of post-hemiplegic painful dystonia following thalamic infarction with good response to botulinus toxin]. Rinsho shinkeigaku 1997;37:881-886.

69 Karsidag S, Özer F, Sen A, Arpaci B: Lesion localization in developing poststroke hand dystonia. Eur Neurol 1998;40:99-104.

70 Apaydin H, Özekmekçi S, Yeni N: Posthemiplegic focal limb dystonia: a report of two cases. Clin Neurol Neurosurg 1998;100:46-50.

71 Miranda M, Millar A: Blepharospasm associated with bilateral infarcts confined to the thalamus: case report. Mov Disord 1998;13: 616-617.

-72 Krystkowiak P, Martinat P, Defebvre L, Pruvo JP, Leys D, Destée A: Dystonia after striatopallidal and thalamic stroke: clinicoradiological correlations and pathophysiological mechanisms. J Neurol Neurosurg Psychiatry 1998;65:703-708.

73 Nakamura Y, Miura K, Yamada I, Takada K: [Disappearance of essential tremor after thalamic infarction]. Rinsho shinkeigaku 1999; 39:340-342.

74 Kao YF, Shih PY, Chen WH: An unusual concomitant tremor and myoclonus after a contralateral infarct at thalamus and subthalamic nucleus. Kaohsiung J Med Sci 1999;15:562-566.

-75 Soler R, Vivancos F, Muñoz-Torrero JJ, Arpa J, Barreiro P: Postural tremor after thalamic infarction. Eur Neurol 1999;42:180-181.

76 Cho C, Samkoff LM: A lesion of the anterior thalamus producing dystonic tremor of the hand. Arch Neurol 2000;57:1353-1355.

-77 Tatu L, Moulin T, Martin V, Monnier G, Rumbach L: Unilateral pure thalamic asterixis: clinical, electromyographic, and topographic patterns. Neurology 2000;54:2339-2342.

-78 Barbaud A, Hadjout K, Blard JM, Pagès M: Improvement in essential tremor after pure sensory stroke due to thalamic infarction. Eur Neurol 2001;46:57-59.

79 Kim JS: Delayed onset mixed involuntary movements after thalamic stroke: clinical, radiological and pathophysiological findings. Brain 2001;124:299-309.
80 Kim JS: Asterixis after unilateral stroke: lesion location of 30 patients. Neurology 2001;56: 533-536.

81 Lee MS, Kim YD, Yang JW, Lyoo CH, Oh SH, Kim HS: Clinical and anatomical factors associated with thalamic dyskinesias. J Neurol Sci 2001;182:137-142.

82 Probst-Cousin S, Druschky A, Neundörfer B: Disappearance of resting tremor after "stereotaxic" thalamic stroke. Neurology 2003;61: 1013-1013.

83 Jungehulsing G, Ploner C: Eyelid tremor in a patient with a unilateral paramedian thalamic lesion. J Neurol Neurosurg Psychiatry 2003, 74:356-358.

84 Chung SJ, Im JH, Lee MC, Kim JS: Hemichorea after stroke: clinical-radiological correlation. J Neurol 2004;251:725-729.

85 Cerrato P, Grasso M, Azzaro C, et al: Palatal myoclonus in a patient with a lateral thalamic infarction. Neurology 2005;64:924-925.

86 Choi SM, Lee SH, Park MS, Kim BC, Kim MK, Cho KH: Disappearance of resting tremor after thalamic stroke involving the territory of the tuberothalamic artery. Parkinsonism Relat Disord 2008;14:373-375.

87 Baysal L, Acarer A, Celebisoy N: Post-ischemic Holmes' tremor of the lower extremities. J Neurol 2009;256:2079-2081.

88 Cho T, Hermier M, Derex L, Trouillas P, Nighoghossian N: Ataxic hemiparesis: the benefit of acute multiparametric magnetic resonance imaging. Arch Neurol 2010;67:116-117.

-89 Pérez-Sánchez S, Fernández-Recio M, LópezDomínguez JM, Sánchez-Sánchez V, ÁlvarezLópez M, Izquierdo-Ayuso G: Thalamic ischaemic stroke: an uncommon aetiology of "startle syndrome". Neurologia 2010;25:138140.

90 Inoue M, Kojima Y, Mima T, et al: Pathophysiology of unilateral asterixis due to thalamic lesion. Clin Neurophysiol 2012;123:18581864.

91 Papuc E, Obszanska K, Trojanowski T, Szczepanska-Szerej H, Rejdak K, Stelmasiak Z: Reduction of thalamic tremor with deep brain stimulation performed for post stroke chronic central pain. Ann Agric Environ Med 2013; 20:45-47.

$\$ 2$ Khooshnoodi MA, Factor SA, Jinnah HA: Secondary blepharospasm associated with structural lesions of the brain. J Neurol Sci 2013;331:98-101

93 Cohen GJ, Tekes A, Ngo TL: Acute-onset choreiform movements in a previously healthy 4-year-old patient. Pediatr Emerg Care 2014;30:31-34.

94 Martinez Alfonzo B, Blanco AE, Rojano J, Calleja JL: Vascular hemichorea: case report and review. Medwave 2014;14:e5936.
-95 Pandey S, Sarma N: Stereotypy after acute thalamic infarct. JAMA Neurol 2015;72: 1068-1068.

96 Hatate J, Miwa K, Matsumoto M, et al: Association between cerebral small vessel diseases and mild parkinsonian signs in the elderly with vascular risk factors. Parkinsonism Relat Disord 2016;26:29-34.

-97 Raina GB, Cersosimo MG, Folgar SS, et al: Holmes tremor: clinical description, lesion localization, and treatment in a series of 29 cases. Neurology 2016;86:931938 .

$\checkmark 98$ Horn A, Kipp L, Meola A, Kühn AA, Leithner C: Teaching neuroImages: stroke mimicking thalamotomy: cessation of tremor following ventrolateral thalamic ischemia. Neurology 2016;87:e208-e209.

-99 Martins WA, Marrone LCP, Fussiger H, et al: Holmes' tremor as a delayed complication of thalamic stroke. J Clin Neurosci 2016; 26:158-159.

100 Hassler R: Architectonic organization of the thalamic nuclei. In: Schaltenbrand G, Walker AE (eds) Stereotaxy of the human brain. Thieme, Stuttgart, 1982, pp 140-180.

101 Hirai T, Jones EG: A new parcellation of the human thalamus on the basis of histochemical staining. Brain Res Brain Res Rev 1989; 14:1-34.

102 Melo TP, Bogousslavsky J, Solomon DH, Barohn RJ: Thalamic ataxia syndrome. Neurology 1995;45:598-599.

103 Flaherty AW, Graybiel AM: Anatomy of the basal ganglia. Mov Disord 1994;3:3-27.

104 Milhorat TH: Experimental myoclonus of thalamic origin. Arch Neurol 1967;17:365378.

105 Mitchell IJ, Boyce S, Sambrook MA, Crossman AR: A 2-deoxyglucose study of the effects of dopamine agonists on the parkinsonian primate brain. Implications for the neural mechanisms that mediate dopamine agonist-induced dyskinesia. Brain 1992;115: 809-824.

106 Gut NK, Winn P: The pedunculopontine tegmental nucleus-A functional hypothesis from the comparative literature. Mov Disord 2016;31:615-624.

107 Ainge JA, Jenkins TA, Winn P: Induction of c-fos in specific thalamic nuclei following stimulation of the pedunculopontine tegmental nucleus. Eur J Neurosci 2004;20: 1827-1837.

108 Neychev VK, Fan X, Mitev VI, Hess EJ, Jinnah HA: The basal ganglia and cerebellum interact in the expression of dystonic movement. Brain 2008;131:2499-2509.

109 Suchowersky O, Comella C: Hyperkinetic Movement Disorders. Humana Press, 2012. 